\title{
Pyogenic Knee Arthritis Caused by Group A $\beta$-Hemolytic Streptococcus: A Toxic Shock-Prevented Case
}

\author{
MASAFUMI GOTO, MASAFUMI GOTOH, YASUHIRO MITSUI, HIDEAKI SHIBATA*, \\ TAKAHIRO OKAWA, FUJIO HIGUCHI AND NAOTO SHIBA* \\ Department of Orthopedic Surgery, Kurume University Medical Center, Kurume 839-0863, \\ *Department of Orthopedic Surgery, Kurume University School of Medicine, Kurume 830-0011, Japan \\ Received 13 May 2013, accepted 29 January 2014 \\ J-STAGE advance publication 25 August 2014
}

Edited by HIROSHI WATANABE

\begin{abstract}
Summary: Pyogenic knee arthritis caused by group A $\beta$-hemolytic streptococcus (GAS) is rare. GAS sometimes causes group A $\beta$-hemolytic streptococcal toxic shock syndrome. We encountered a case of pyogenic knee arthritis caused by GAS that resolved after appropriate treatment (emergency arthroscopic synovectomy and medication) administered within $48 \mathrm{~h}$ of onset. In cases of a history of another infection with acute knee joint pain, the possibility of GAS-induced pyogenic knee arthritis should be considered, and proper treatment should be administered immediately.
\end{abstract}

Key words pyogenic knee arthritis, group A $\beta$-hemolytic streptococcus, streptococcal toxic shock syndrome

\section{INTRODUCTION}

Group A $\beta$-hemolytic streptococci (GAS) are well known to cause bacterial pharyngitis and superficial skin infections such as erysipelas and cellulitis. Additionally, GAS is classically associated with the nonsuppurative complications of poststreptococcal glomerulonephritis and acute rheumatic fever [1]. GAS infects the human body via skin injury or varicella [2]. A clinical feature of GAS infections is abrupt onset [3], and patients with this disease are admitted to the hospital with high-grade fever and marked leukocytosis $[3,4]$.

GAS is also the causative bacterium in necrotizing fasciitis and group A $\beta$-hemolytic streptococcal toxic shock syndrome (STSS). STSS presents with fulminant shock and rash, is rapidly progressive with multiple organ dysfunction syndrome, and requires aggressive therapy with fluids, antibiotics, and source control [5]. In this study, we report the successful treatment of pyogenic knee arthritis caused by GAS.

\section{CASE REPORT}

The patient was a 70-year-old woman without prior knee pain. She had a 1-week history of symptoms of cold that were associated with pharyngeal pain, for which she did not seek treatment. She experienced acute left knee joint pain (disease day 1) that worsened the next day (disease day 2) and rendered her unable to walk. A local doctor performed a medical examination that day. Aspiration of the left knee was performed and the specimen was sent for bacterial culture.

Purulent knee arthritis was suspected, and the patient was immediately referred to our hospital. During the patient's first examination, her level of consciousness was clear. Her blood pressure was $162 / 98 \mathrm{mmHg}$, pulse rate was 85 beats/min, body temperature was $37.2^{\circ} \mathrm{C}$, and lung and heart sounds were normal. The patient complained of severe general malaise, and she

Corresponding Author: Masafumi Gotoh, MD. Department of Orthopedic Surgery, Kurume University Medical Center 155-1 Kokubu-machi, Kurume, Fukuoka 830-0037, Japan. Tel: +81 -942-22-6111 (ex. 533) Fax: +81-942-22-6657 E-mail: gomasa@med.kurume-u.ac.jp

Abbreviations: CT, computed tomography; GAS, group A $\beta$-hemolytic streptococcus; MRI, magnetic resonance imaging; POD, postoperative day; STSS, streptococcal toxic shock syndrome 
appeared to be in agony from severe pain. Mild swelling, redness, and a burning sensation of the left knee were observed. However, there was no visible wound or history of intra-articular injection. The synovial fluid immediately extracted from the left knee joint was turbid and dark red in color; it was sent for bacterial culture to another institutional laboratory (SRL, Fukuoka, Japan). The synovial fluid was centrifuged at $3000 \mathrm{rpm} / \mathrm{min}$ for $10 \mathrm{~min}$. The pellet was seeded on trypticase soy agar II with 5\% sheep blood agar/chocolate II agar (Japanese Beckton Dickinson, Tokyo, Japan) and incubated $\left(35^{\circ} \mathrm{C}, 5 \% \mathrm{CO}_{2}\right)$. Next, streptococci were isolated on Strepto LA (Denka Seiken, Tokyo, Japan) using $\beta$-hemolytic colonies. It required several days to identify GAS.

The results of a blood test on admission revealed a marked inflammatory reaction with a leukocyte count of $19,760 / \mu \mathrm{L}$ (87.0\% neutrophils), and a C-reactive protein (CRP) level of $14.59 \mathrm{mg} / \mathrm{dL}$. Mild hepatic dysfunction (total bilirubin [T.B.], $1.4 \mathrm{mg} / \mathrm{dL}$; aspartate aminotransferase [AST], $150 \mathrm{U} / \mathrm{L}$; alanine aminotransferase [ALT], $142 \mathrm{U} / \mathrm{L}$ ) and renal dysfunction (blood urea nitrogen [BUN], $18.0 \mathrm{mg} / \mathrm{dL}$; creatinine, $1.1 \mathrm{mg} /$ $\mathrm{dL}$ ) were also observed. There was no coagulation abnormality. Glycated hemoglobin level was also within the normal range.

Magnetic resonance imaging (MRI) was scheduled, but because of the severity of the patient's left knee pain, early-stage surgery was deemed necessary. Emergency arthroscopic synovectomy, cleansing, and

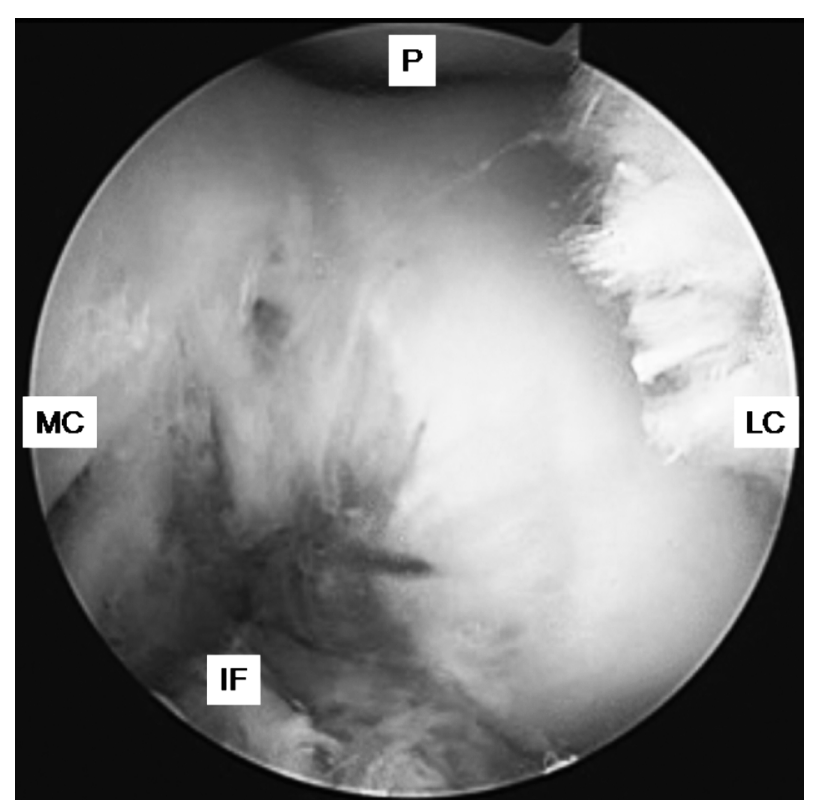

Fig. 1. Arthroscopic image.

$\mathrm{P}=$ patella; $\mathrm{MC}=$ medial condyle; $\mathrm{LC}=$ lateral condyle; IF=intercondylar fossa drainage were performed soon after hospitalization (disease day 2) (Fig. 1). Moderate redness and synovial proliferation were observed in the femoropatellar and femorotibial joints during arthroscopy. Cefazolin (4.0 $\mathrm{g}$ /day) was prescribed until the causative bacterium was identified. Results from blood tests performed on postoperative day (POD) 2 (disease day 4) showed a leukocyte count of 30,250/ $\mu \mathrm{L}$ (91.0\% neutrophils) and a CRP level of $43.40 \mathrm{mg} / \mathrm{dL}$.

On POD 3 (disease day 5), GAS was identified as the causative bacterium from the synovial fluid culture both before admission and at this hospital. Cefazolin was replaced with ampicillin/cloxacillin ( $8 \mathrm{~g} /$ day) and clindamycin $(1,800 \mathrm{mg} / \mathrm{day})$ based on the results of the antibiotic susceptibility test (Table 1 ). To confirm that there were no other infections outside the knee joint, a blood culture, echocardiography, and contrastenhanced computed tomography (CT) were performed. No abnormality was found. After continuous intravenous antibiotics and drainage, the inflammatory reactions and severe left knee pain gradually improved (Fig. 2). On POD 14 (disease day 16), contrast-enhanced

TABLE 1.

Chemical sensitivity test

\begin{tabular}{cl}
\hline Benzylpenicillin & $\mathrm{S}$ \\
Ampicillin & $\mathrm{S}$ \\
Piperacillin & $\mathrm{S}$ \\
Cefazolin & $\mathrm{S}$ \\
Cefaclor & $\mathrm{S}$ \\
Cefotiam & $\mathrm{S}$ \\
Cefpirome & $\mathrm{S}$ \\
Cefozopran & $\mathrm{S}$ \\
Cefdinir & $\mathrm{S}$ \\
Cefcapene pivoxil & $\mathrm{S}$ \\
Cefminox & $\mathrm{R}$ \\
Flomoxef & $\mathrm{S}$ \\
Imipenem/cilastatin & $\mathrm{S}$ \\
Faropenem & $\mathrm{S}$ \\
Tazobactam/piperacillin & $\mathrm{S}$ \\
Erythromycin & $\mathrm{R}$ \\
Clarithromycin & $\mathrm{R}$ \\
Clindamycin & $\mathrm{S}$ \\
Minocycline & $\mathrm{S}$ \\
Sparfloxacin & $\mathrm{S}$ \\
Levofloxacin & $\mathrm{S}$ \\
Fosfomycin & $\mathrm{S}$ \\
\hline
\end{tabular}

$\mathrm{S}=$ sensitive; $\mathrm{R}=$ resistant 


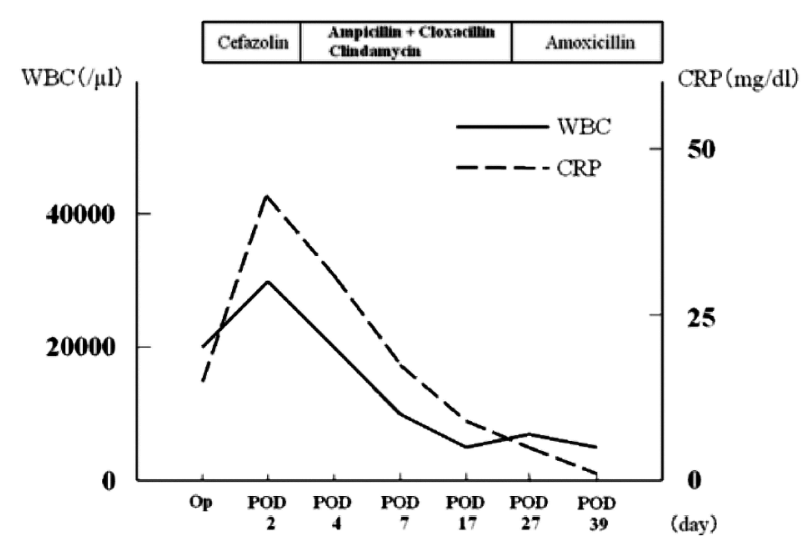

Fig. 2. A transition of the inflammatory markers. $\mathrm{WBC}=$ white blood cell; $\mathrm{CRP}=\mathrm{C}$-reactive protein; $\mathrm{Op}=$ operation; $\mathrm{POD}=$ postoperative day

MRI revealed residual edema in the joint; however, there was no sign of extra-articular necrotizing fasciitis.

Because inflammatory reactions were negative, the patient was discharged on POD 71 (disease day 73). No recurrent pain was noted at the 2-year followup visit, and the patient had no difficulty with daily life activities (e.g., walking independently).

\section{DISCUSSION}

Staphylococcus aureus is responsible for $>60 \%$ of bacteriologically documented nongonococcal septic arthritis cases [6], followed by streptococci in approximately $20-30 \%$ of cases [6,7]. Dubost et al. reported that of 303 cases of septic arthritis, 55 (18\%) were caused by streptococci and $166(55 \%)$ by $S$. aureus [3]. They also reported 5 cases $(1.7 \%)$ of GAS-induced pyogenic knee arthritis [3].

The occurrence rate of STSS following GASinduced knee arthritis has not been well documented. Suankratay et al. retrospectively evaluated invasive GAS infections in 42 cases [8]: 13 cases (31\%) of skin infections, 12 cases (29\%) of soft tissue infections, 12 cases (29\%) of primary bacteremia, and 12 cases of arthritis (14\%). Invasive GAS infection is defined by the isolation of GAS from normally sterile body sites and includes bacteremia, necrotizing fasciitis, osteomyelitis, and septic arthritis [9]. Of these, 24 cases $(57 \%)$ progressed to STSS and the eventual mortality rate was 33\% (7 cases) [8]. In this study, we successfully prevented the progression of invasive GASinduced to STSS by performing urgent arthroscopic surgery within $48 \mathrm{~h}$ of onset of infection.
According to the Diagnostic Criteria for Streptococcal TSS (CDC 2010) [10], the diagnosis of STSS is based on the presence of 3 criteria: isolation of GAS from a sterile site, hypotension (systolic blood pressure $<90 \mathrm{mmHg}$ in adults or less than the fifth percentile by age for children aged $<16$ years), and multiple organ involvement characterized by 2 or more of the following: renal impairment (creatinine level greater than or equal to twice the upper limit of normal for age), coagulopathy (platelet count $\leq 100,000 / \mathrm{mm}^{3}$ or disseminated intravascular coagulation), liver involvement (alanine aminotransferase [ALT], aspartate aminotransferase [AST], or total bilirubin [T.B.] levels greater than or equal to twice the upper limit of normal), acute respiratory distress syndrome, a generalized erythematous macular rash that may desquamate, and soft-tissue necrosis including necrotizing fasciitis or myositis, or gangrene [10]. The mortality rates in patients with STSS are reportedly as high as $30-70 \%$ [11]. In our study, the patient did not exhibit symptoms of shock, such as hypotension; therefore, STSS was ruled out. However, the presence of severe general malaise and mild liver and renal dysfunction suggest that the patient could have progressed to STSS on disease day 2 if treatment had been delayed.

GAS is susceptible to beta-lactams (penicillin G, amoxicillin, cephalosporins) [12]. Although standard antibiotic treatment has not been defined, antibiotics are generally administered intravenously until CRP levels normalize, followed by daily oral administration for an additional 6 weeks [12]. The prognosis is usually satisfactory unless early diagnosis and appropriate therapy are delayed [12]. Otherwise, delayed treatment results in serious sequelae [12]. In this report, a combination of ampicillin and cloxacillin ( $8 \mathrm{~g} /$ day $)$, to which GAS is sensitive, and clindamycin $(1,800$ $\mathrm{mg}$ /day), which acts irrespective of inoculum size, is a potent suppressor of bacterial toxin synthesis, facilitates phagocytosis, and has a longer postantibiotic effect than beta-lactams $[13,14]$, was chosen and administered for 3 weeks. After the inflammatory reactions subsided, the antibiotics were switched to oral amoxicillin $(1,000 \mathrm{mg} /$ day $)$; this dosage was gradually reduced based on the patient's inflammatory status. At her 6-month follow-up visit, the patient had a well-controlled inflammatory reaction (leukocyte count, $4, / \mu \mathrm{L}$ [46.8\% neutrophils]; CRP, $0.16 \mathrm{mg} / \mathrm{dL}$ ] without antibiotics. There are no established guidelines for the duration of antibiotic use; therefore, it remains to be clarified in future investigations.

In conclusion, we report on a successful surgery that was performed within $48 \mathrm{~h}$ of the onset of a rare 
case of GAS-induced pyogenic knee arthritis, and propose that this case did not become more serious because the articular capsule served as a barrier that retained the bacteria and exotoxins inside the joint. Consequently, only synovectomy, cleansing, and drainage were performed to protect the articular capsule. In cases with a history of a separate infection combined with acute knee joint pain and marked general malaise, the possibility of GAS-induced pyogenic knee arthritis should be considered, and treatment should be administered immediately.

\section{REFERENCES}

1. Martin JM, and Green M. Group A streptococcus. Semin Pediatr Infect Dis. 2006; 17:140-148.

2. Abuhammour W, Hasan RA, and Unuvar E. Group A betahemolytic streptococcal bacteremia. Indian J Pediatr. 2004; 71:915-919.

3. Dubost JJ, Soubrier M, De Champs C, Ristori JM, and Sauvezie B. Streptococcal septic arthritis in adults. A study of 55 cases with a literature review. Joint Bone Spine. 2004; 71:303-311.

4. Schattner A, and Vosti KL. Bacterial arthritis due to betahemolytic streptococci of serogroups A, B, C, F and G. Analysis of 23 cases and a review of the literature. Medicine. 1998; 77:122-139.

5. Krishna V, Sankaranarayan S, Sivaraman RP, and Prabaharan K. Streptococcal toxic shock syndrome. Indian
J Pediatr. 2013 Dec 3. [Epub ahead of print]

6. Dubost JJ, Soubrier M, and Sauvezie B. Pyogenic arthritis in adults. Joint Bone Spine. 2000; 67:11-21.

7. Ryan MJ, Kavanagh R, Wall PG, and Hazleman BL. Bacterial joint infections in England and Wales: analysis of bacterial isolates over a four year period. $\mathrm{Br} J$ Rheumatol. 1997; 36:370-373.

8. Suankratay C, Nunthapisud P, and Wilde H. Invasive group A streptococcal infections at Chulalongkorn University Hospital. J Med Assoc Thai. 2001; 84(11):1594-1603.

9. American Academy of Pediatrics, Committee on Infectious Disease. Severe invasive group A streptococcal infections: a subject review. Pediatrics. 1998; 101:136-140.

10. Streptococcal Toxic Shock Syndrome (STSS). CDC Case definition 2010. Available from:http://wwwn.cdc.gov/ nndss/script/casedef.asp $\mathrm{x}$ ?Cond Y rID $=858 \&$ DatePub $=$ 1/1/2010\%2012:00:00\%20AM

11. Demers B, Simor AE, Velland H, Schlievert PM, Byme S et al. Severe invasive group A streptococcal infections in Ontario, Canada: 1987-1991. Clin Infect Dis. 1993; 16:792800. discussion 801-802.

12. Laatiris A, Amine B, Ibn Yacoub Y, and Hajjaj-Hassouni N. Septic polyarthritis caused by group A streptococcus in an immunocompetent adult: rare case. Rheumatol Int. 2012; 32:2697-2700

13. Stevens DL. Streptococcal toxic-shock syndrome: spectrum of disease, pathogenesis, and new concepts in treatment. Emerg Infect Dis. 1995; 1:69-78.

14. Morales MV, Navarro CJS, Lletí MS, Alonso MM, Bellés $\mathrm{CP}$ et al. Group A streptococcal bacteremia: Outcome and prognostic factors. Rev Esp Quimioter. 2006; 19:367-375. 